\title{
An Unusual Cause of Failed Tracheal Decannulation-A Case Report
}

\author{
Sailaja Kambhampati ${ }^{1}$, K Lavanya $^{2}$
}

\begin{abstract}
Failure of decannulation may occur due to unexpected upper airway problems. However, the presence of a membrane in between the vocal cords is usually rare. We report a case of a 46 -year-old female, who presented with focal seizures and progressed to status epilepticus. She was put on a mechanical ventilator because of hypoxic arrest. As she required prolonged ventilatory support, tracheostomy and gradual weaning from ventilator support to T-piece was done. Following stable hemodynamics, decannulation trial was attempted which failed. Subsequently, bronchoscopy was done to assess the upper airway. It revealed a thick membrane in between the vocal cords. Further examination with an indirect laryngoscope under general anesthesia confirmed the findings, and the membrance was excised. Decannulation was successful the very following day and the patient was discharged with stable hemodynamics.
\end{abstract}

Keywords: Decannulation, Failure, Membrane, Vocal cords, Weaning

Indian Journal of Critical Care Medicine (2019): 10.5005/jp-journals-10071-23223

\section{INTRODUCTION}

A tracheostomy tube is placed for several reasons: to bypass an upper airway obstruction, failure to wean from mechanical ventilation, impaired neurologic status, and inability to handle excessive secretions..$^{1-3}$ The placement of a tracheostomy tube facilitates the transfer of the patient from the intensive care unit to a weaning facility such as a step-down unit or a long-term care hospital. ${ }^{4}$ A tracheostomy may be only a short-term requirement for patients and should be removed as soon as it is no longer needed. Decannulation describes the process of tracheostomy tube removal once the need for the tube has resolved. Advantages of decannulation include improved vocal cord and swallowing function, improved patient comfort and perceived physical appearance. Decannulation failure is defined as reinsertion of an artificial airway within 48-96 hours after tube removal.

\section{Case Description}

A 46-year-old obese, hypertensive, denovo hypothyroid female presented with focal seizures and altered sensorium which progressed to status epilepticus. On assessment, GCS was E4M5V2, pupils were bilaterally reacting to light, hemodynamics were stable, and lungs clear on auscultation. She was being treated with dual antiepileptics, thyroxine, and supportive medication. MRI brain was suggestive of encephalitis, probably of viral or autoimmune etiology (anti-TPO antibodies 901; ANA profile negative; TSH-9.77). Chest radiograph showed mild cardiomegaly (Fig. 1).

She was put on a mechanical ventilator three days later because of severe bronchospasm and hypoxic arrest. Five days later, tracheostomy was done as she required prolonged assisted ventilation, tracheostomy was done five days later. Gradual weaning was initiated thereafter. Following stable hemodynamics and resolving primary etiology, decannulation was done. Within minutes, the patient developed severe hypoxia and had to be recannulated immediately. The subsequent attempt, five days later, was a similar failure. Then, video-assisted bronchoscopy was performed to assess the airway. It revealed a white, fixed membrane in between the vocal cords (Figs 2 and 3 ).
${ }^{1}$ Department of Pulmonary Medicine, Maxcure Hospital, Hyderabad, Telangana, India

${ }^{2}$ Department of Pulmonology, Maxcure Hospital, Hyderabad, Telangana, India

Corresponding Author: Sailaja Kambhampati, Department of Pulmonary Medicine, Maxcure Hospital, Hyderabad, Telangana, India, e-mail: ksailaja02@hotmail.com

How to cite this article: Kambhampati S, Lavanya K. An Unusual Cause of Failed Tracheal Decannulation-A Case Report. Indian J Crit Care Med 2019;23(8):378-379.

Source of support: Nil

Conflict of interest: None

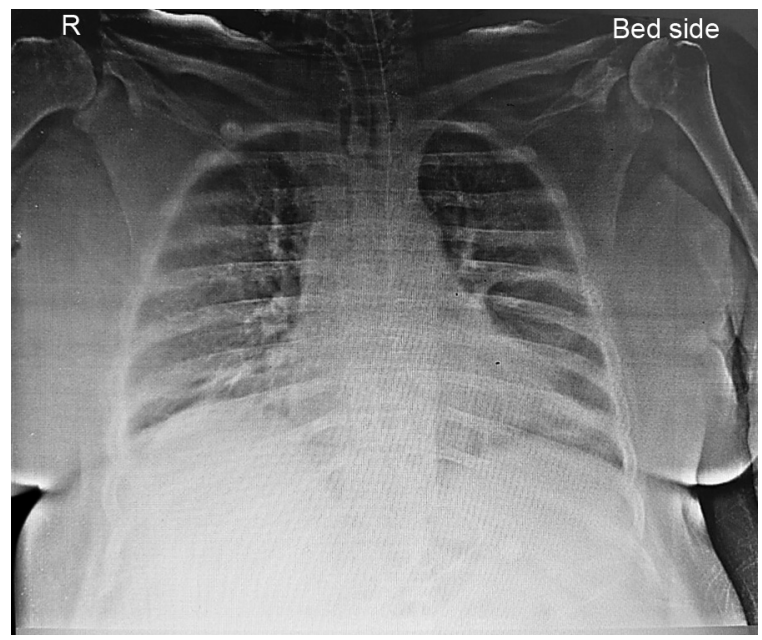

Fig. 1: Chest radiograph showing cardiomegaly

Further examination by an otorhinolaryngologist with an indirect laryngoscope proved it to be a membrane, which was promptly excised. The patient was successfully decannulated the very next day and discharged 3 days later with stable hemodynamics (Fig. 4).

(0) The Author(s). 2019 Open Access This article is distributed under the terms of the Creative Commons Attribution 4.0 International License (https://creativecommons. org/licenses/by-nc/4.0/), which permits unrestricted use, distribution, and non-commercial reproduction in any medium, provided you give appropriate credit to the original author(s) and the source, provide a link to the Creative Commons license, and indicate if changes were made. The Creative Commons Public Domain Dedication waiver (http://creativecommons.org/publicdomain/zero/1.0/) applies to the data made available in this article, unless otherwise stated. 


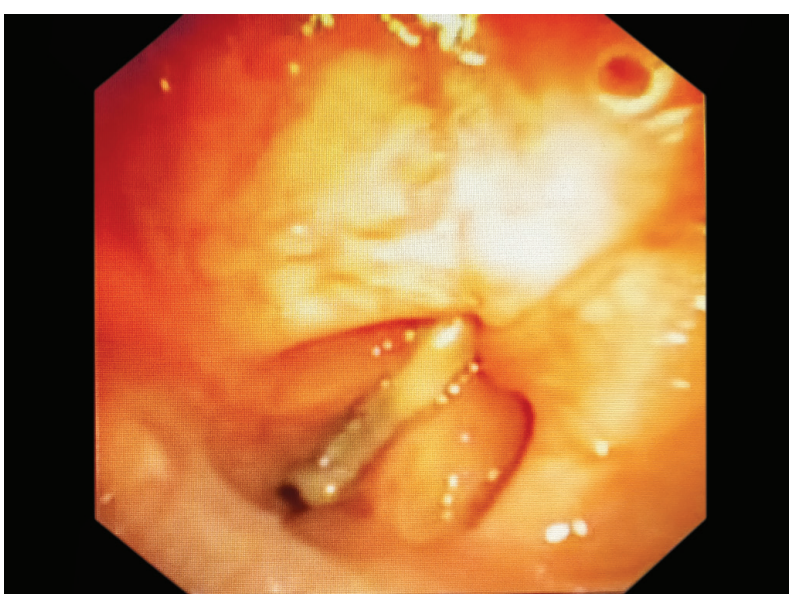

Fig. 2: Fixed and adducted vocal cords seen through a bronchoscopy

\section{Discussion}

Variable degrees of airway obstruction are frequently seen post tracheostomy. The incidence of obstructive lesions in prospective and retrospective examination studies range from $20 \%$ and $67 \%$ in patients with long-term tracheostomy tubes. ${ }^{5-7}$ Obstruction commonly occurs at the site in contact with cuff, the tip of tube and stoma. ${ }^{8-10}$ It may present as granulations $(58 \%)^{6}$, tracheomalacia $(29-45 \%)^{6,10}$ nodulations, polypoids, fibrosis or scarring with constricture or stenosis (14-64\%). ${ }^{5,6,10}$ Decannulation is usually well tolerated. Success and failure of decannulation is defined in different ways by different groups. One group defines success as extubation or decannulation and site closure with no consequent respiratory symptoms or blood gas deterioration for at least two weeks and failure is defined as the appearance of respiratory distress and decreases in vital capacity and oxyhemoglobin saturation despite the use of noninvasive IPPV and assisted coughing. Another definition of failure is reinsertion of an artificial airway within 48-96 hours after tracheostomy decannulation. The acceptable decannulation failure rate is reported to range from $2 \%$ and $5 \% .{ }^{11} \mathrm{~A}$ systematic approach to patient evaluation, along with judicious use of airway endoscopy, can help identify barriers to decannulation. Fiber optic bronchoscopy allows direct visualization and assessment of the whole upper airway including larynx and trachea above and below the stoma. Assessment of the anatomical, as well as the physiological status of the upper airway, helps in decannulation as well as post decannulation care.

\section{Conclusion}

Even though the incidence of decannulation complications may be low, ${ }^{12}$ they can be disastrous and life-threatening. Direct visual inspection with a video-assisted bronchoscope not only enhances the decannulation process but also detects correctable lesions at an early stage. Bronchoscopy is, thus, an invaluable tool in difficult cases of tracheostomy decannulation.

\section{References}

1. Frutos-Vivar F, Esteban A, Apezteguía C, Anzueto A, Nightingale P, Gonza'lez M, et al. Outcome of mechanically ventilated patients who require a tracheostomy. Crit Care Med 2005;33(2):290-298.

2. Esteban A, Anzueto A, Alía I, Gordo F, Apezteguía C, Pa'lizas F, et al. How is mechanical ventilation employed in the intensive care

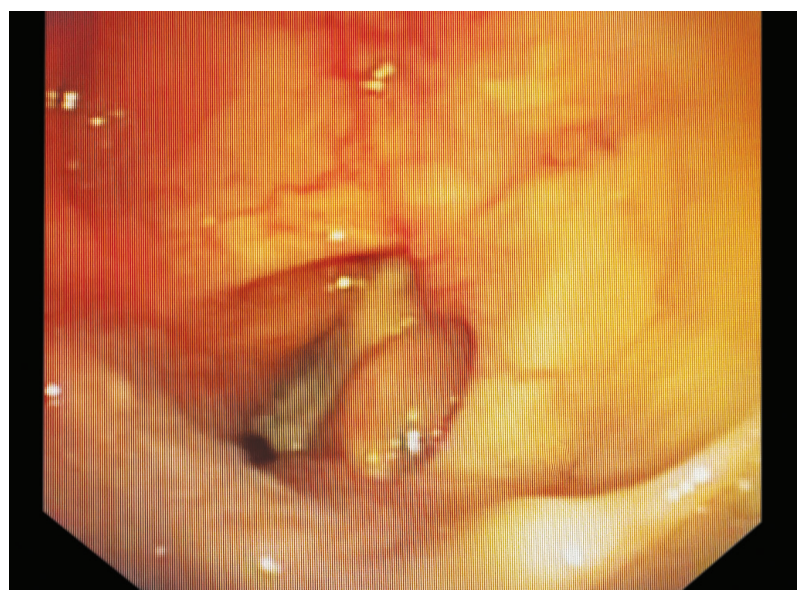

Fig. 3: Adducted vocal cords

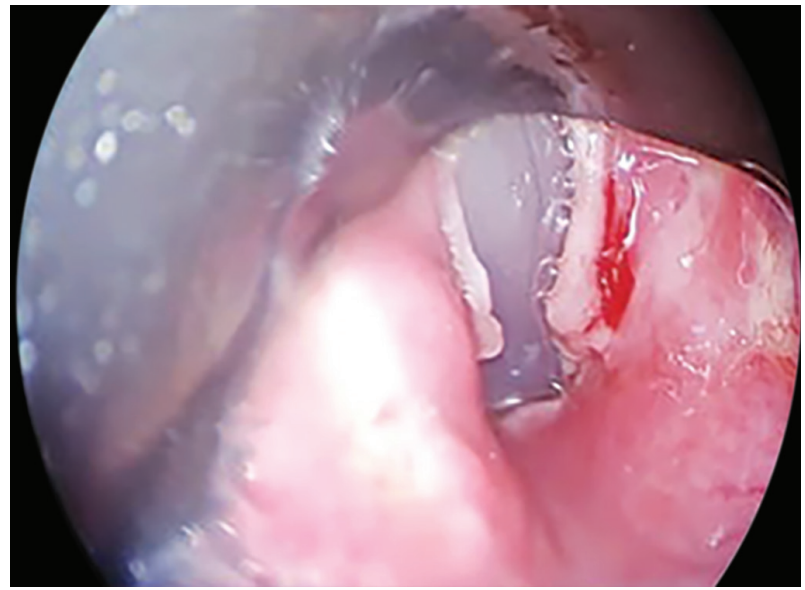

Fig. 4: Incised vocal cords showing normal space between the two

unit? An international utilization review. Am J Respir Crit Care Med 2000;161(5):1450-1458.

3. Kollef MH, Ahrens TS, Shannon W. Clinical predictors and outcomes for patients requiring tracheostomy in the intensive care unit. Crit Care Med 1999;27(9):1714-1720.

4. Scheinhorn DJ, Chao DC, Stearn-Hassenpflug M, LaBree LD, Heltsley DJ. Post-ICU mechanical ventilation: treatment of 1,123 patients at a regional weaning center. Chest 1997;111(6):1654-1659.

5. Stauffer JL, Olson DE, Petty TL. Complications and consequences of endotracheal intubation and tracheotomy. A prospective study of 150 critically ill adult patients. Am J Med 1981:70:65-76.

6. Law JH, Bamhart K, Rowlett W, de la Rocha 0, Lowenberg S. Increased frequency of obstructive airway abnormalities with a long-term tracheostomy. Chest 1993;104:136-138.

7. Heffner JE, Miller KS, Sahn SA. Tracheostomy in the intensive care unit. Part I: Indications, technique, management. Chest 1986;90:269-274.

8. Heffner JE. Miller KS. Sahn SA. Tracheostomy in the intensive care unit. Part 2: Complications. Chest 1986;90:430-436.

9. Siddharth P, Mazzarella L. Granuloma associated with fenestrated tracheostomy tubes. Am J Surg 1985;150:279-280.

10. Dane TEB, King EG. A prospective study of complications after tracheostomy for assisted ventilation. Chest 1975;67:398-404.

11. Stelfox HT, Hess DR, Schmidt UH. A North American survey of respiratory therapist and physician tracheostomy decannulation practices. Respir Care 2009;54(12):1658-1664.

12. McClelland RMA. Complications of tracheostomy. BMJ 1965;2:567-569. 